\title{
cmaJOPEN
}

\section{Outreach physiatry clinics in remote Manitoba communities: an economic cost analysis}

\author{
Janine N. Reid MD, Karen D. Ethans MD, Brian Chun-Fai Chan PhD
}

\section{Abstract}

Background: One in 5 people in Canada have a disability affecting daily activities, and, for rural patients, accessing lifelong physiatry care to improve function and manage symptoms requires complex and expensive travel. We compared the costs of new outreach physiatry clinics with those of conventional urban clinics in Manitoba.

Methods: Six outreach clinics were held from January 2018 to September 2019 in the remote communities of St. Theresa Point and Churchill, Manitoba. A general physiatry population was seen in these clinics, including patients with musculoskeletal and neurologic conditions seen in consultation and follow-up. We performed a societal cost-minimization analysis comparing outreach clinic costs to estimated costs of standard care at conventional outpatient clinics in Winnipeg. Outcomes of interest included direct costs to government health services and patients, and indirect opportunity cost of travel time. We calculated total costs, average cost per clinic visit and incremental costs for outreach clinics compared to conventional urban clinics. Costs were inflated to 2020 Canadian dollars.

Results: Thirty-one patients (48 visits) were seen at the outreach clinics. The total cost of providing outreach clinics, $\$ 33136$, was $21 \%$ of the estimated cost of standard care, $\$ 158344$. When only direct costs were included, outreach clinics cost an estimated $24 \%$ of conventional care costs. The average unit cost per outreach visit was $\$ 690$, compared to $\$ 3299$ per conventional visit, for an incremental cost of $-\$ 2609$ per outreach visit.

Interpretation: An outreach physiatry visit in Manitoba cost an estimated $21 \%$ of a conventional urban outpatient visit, or $24 \%$ when only direct costs were included, with costs savings largely related to travel. Outreach physiatry care in this model provides substantial cost savings for the public health care system as the primary payer, and can reduce the travel cost burden for patients who do not have public travel funding.

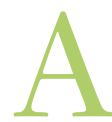

bout 1 in 5 adults in Canada live with a disability resulting from a chronic condition such as stroke, spinal cord injury, amputation or brain injury that limits their daily activity. ${ }^{1}$ People with these conditions commonly have a higher risk for death as a consequence of chronic, manageable complications (such as bladder, skin or respiratory infection), cardiovascular events and suicide. ${ }^{2,3}$ For these patients, care by a physiatrist and lifelong patientcentred rehabilitation are important in the management of symptoms and prevention of complications, in addition to curative treatment. The primary model of care delivery for these services centres around the outpatient setting.

Twenty percent of people in Canada live in small centres (population < 30000 ). ${ }^{4}$ Access to specialized physiatry services by rural patients is limited in Canada owing to centralization of these services in urban tertiary hospital environments. Rural patients requiring rehabilitation must travel, with variable public funding. Geography and care needs compounded by social determinants of health result in complicated, expensive transportation, overnight stays, weather-related delays, the need for attendants to support activities of daily living, unfamiliar environments, and disconnection from family and community supports. ${ }^{5}$ For Indigenous patients in Canada, who report disproportionate disability, complexity in access to care is further complicated by funding gaps and racism. ${ }^{6-10}$ Fulfilling the Canada Health Act mandate of equal access to care requires understanding these intersecting barriers ${ }^{11}$ while also recognizing the benefits and resiliencies of patients' remaining in their rural communities, such as maintaining social roles and inclusion. ${ }^{7,12-14}$

Compared to telehealth, visiting specialist outreach services improve access for the rural population requiring physiatry

Competing interests: Karen Ethans reports professional fees from Spectrum Therapeutics, CanniMed, Ipsen and Allergan, and grants from the Praxis Spinal Cord Institute, outside the submitted work. No other competing interests were declared.

This article has been peer reviewed.

Correspondence to: Janine Reid, reidphysiatry@gmail.com

CMAJ Open 2021 August 26. DOI:10.9778/cmajo.20200234 
care by enabling the essential components of specialized physical examination, such as detailed musculoskeletal and neurologic examination, and interventional treatments such as chemodenervation injections for spasticity. ${ }^{15}$ Systematic reviews examining specialist outreach showed that health outcomes were generally similar to or better than conventional care (i.e., urban outpatient physiatry clinics). ${ }^{16,17}$ Rural outreach consultation was found to increase guideline-based care in oncology and orthodontics, ${ }^{18,19}$ increase consultations in general and specialty surgery, ${ }^{17}$ and maintain safety and health outcomes in cataract surgery. ${ }^{20}$

Outreach physiatry clinics were developed in 2 remote communities in Manitoba. They primarily followed a shifted outpatient model to replicate conventional urban outpatient clinics, ${ }^{17}$ with the goal of providing equivalent care. Our aim in the present study was to consider the preliminary economic cost implications of these outreach clinics and compare their societal costs with the estimated costs of seeing the same patients in conventional urban outpatient physiatry clinics. ${ }^{21}$

\section{Methods}

\section{Study design}

We conducted a cost-minimization analysis, a method used in health economics when comparing costs of 2 similar interventions. This study design is appropriate for comparing the cost of health care treatment alternatives with similar health outcomes. ${ }^{16,17} \mathrm{We}$ used the societal perspective of people living in rural Manitoba in order to include direct costs to the health care system, and also direct and indirect costs to patients and providers.

\section{Setting}

The main physiatry services for Manitoba are in Winnipeg, at the Health Sciences Centre and Riverview Health Centre. Two outreach services were developed in collaboration with local health services in the remote northern communities of St. Theresa Point (Oji-Cree First Nation, population about 3300) and Churchill (rural municipality, population about 900). ${ }^{4}$ The selection of communities for clinics was motivated by existing relationships with local health care providers, regional health authority collaboration with direct written requests for outreach physiatry care, familiarity with Ongomiizwin Health Services specialist outreach programs, and identified highneeds populations for outpatient physiatry care.

The outreach clinics were provided within a specialist shifted outpatient model. In both outreach and conventional clinics, patients were provided comparable consultation with a physiatrist, including potential interaction with a senior resident, follow-up visits, and management such as investigation and procedural treatments. The primary difference between the 2 models was geographic location.

We conducted the outreach physiatry clinics between January 2018 and September 2019. There were 6 clinic dates, with 3 clinics about every 6 months at either remote service. The physiatrist team, consisting of 1 attending physician and 1 resident physician, provided 1 -day clinics of about
6-8 hours' duration, and carried specialized equipment (portable electromyography-stimulator unit, portable ultrasonography unit). Resident inclusion in the clinic models is standard for Ongomiizwin Health Services and is multipurpose for service provision, education and rural recruitment.

Travel access to the communities is complex and is limited to expensive domestic turboprop flights for both communities, winter ice road, helicopter or boat to St. Theresa Point, and a 2-day train trip to Churchill. Clinics used flights for access, with 2-way travel time of about 7 hours to St. Theresa Point and about 5 hours to Churchill.

Funding for the clinics was provided through Ongomiizwin Health Services, which facilitated logistic support and physician stipend through contracts with Manitoba Health and the federal Non-Insured Health Benefits program.

\section{Participants}

Outreach services were advertised in advance via email and word of mouth, and referrals were received from local family doctors, nursing station staff, Winnipeg physiatry and rehabilitation services, adjacent specialties (e.g., neurosurgery) and self-referral. The patient populations seen in outreach represent a generalist physiatry practice and included adult and pediatric patients with spinal cord injury, traumatic brain injury, cerebral palsy, amputation, musculoskeletal conditions or chronic pain, and those requiring neuromuscular and electrodiagnostic services. Initial and follow-up assessment of common rehabilitation complications included spasticity, mobility issues, neurogenic bowel and bladder, chronic pain, chronic wounds and entrapment neuropathy. Required inperson interventions included botulinum toxin injection, segmental neuromyotherapy and electrodiagnostics.

\section{Data sources}

We examined the costs of care for all outreach clinic visits during the study period and compared them to the costs of bringing those patients to the conventional urban outpatient setting. We identified outcomes of direct and indirect costs to government health services (Manitoba Health, the NonInsured Health Benefits program, Ongomiizwin Health Services), providers and patients. ${ }^{22-24}$ Appendix 1 (available at www.cmajopen.ca/content/9/3/E818/suppl/DC1) provides a list of study costs and assumptions.

We categorized direct costs attributed to government health services and patients into travel, staff and living. We included travel costs for doctors, patients and attendants for all modes of travel, which vary seasonally and which we accounted for proportionally using actual costs and standard mileage costs (airplane, helicopter, boat, taxi, health centre vehicle). ${ }^{22-26}$ The need for attendants to travel to Winnipeg was assessed for each patient by the involved physicians and totalled as total attendant trips.

Staff costs for outreach clinics included the recurring attending physician stipend per clinic day in lieu of billing fees, and general administration by Ongomiizwin Health Services including travel logistic support, and clinic management and coordination with the local health centre. For conventional 
clinics, staff costs included attending physician billing and specialized nursing salary. ${ }^{27,28}$ Staffing costs for both clinic types included resident physician salary and clinic administration staff salary. ${ }^{27,29,30} \mathrm{We}$ excluded costs for clinic space, portable equipment, transcription services, medications, clinic supplies, referrals and investigations as they would be medically necessary and were assumed to be equivalent in the 2 locations.

Living costs included overnight accommodation for patients and attendants at a hotel adjacent to the tertiary hospital and daily food stipend. There were no accommodation costs for the outreach staff as the clinics were single-day clinics with fly in and out on the same day.

For indirect costs, we included the cost of time required to receive or provide care (opportunity cost) that could otherwise be used for work, household production or leisure. ${ }^{22,23}$ For patients and attendants, the total time to receive care in an urban setting included travel from their home community, an overnight stay and travel back home the following day $(1.5 \mathrm{~d})$, with an assumption of a maximum of 8 hours per day. We multiplied the hours of travel for patients and attendants and for the resident physician by an hourly value of work time calculated from the average yearly employment income for a person working in Canada and from the average yearly salary for a resident physician in Manitoba, respectively. ${ }^{29,30,31}$ The attending physician stipend included remuneration for travel time.

Independently and in duplicate, 2 investigators (J.N.R. and K.D.E.) extracted costs data for service provision from existing quality-assurance data collected by Ongomiizwin Health Services, and from the relevant administrative and health care providers for both models of care delivery and both communities. The data were verified for accuracy by Ongomiizwin Health Services administrative staff, and discrepancies were resolved through consensus. Input costs reported from prior years were inflated to 2020 Canadian dollars. ${ }^{32}$ The physiatrists involved in the outreach clinics recorded the numbers of patients, type of visit, number of attendants and travel mode that would have been required to access conventional care in Winnipeg based on patient functional needs.

\section{Statistical analysis}

We calculated total costs of outreach and conventional clinics, including breakdown by cost type (travel, staff, living), average unit cost per patient clinic visit, and incremental costs for outreach compared to conventional clinics.

We conducted 1-way sensitivity analyses to examine the robustness of the cost-minimization analysis to changes in the cost inputs. Single inputs were varied one at a time, and the total incremental costs were recalculated. The ranges of cost input changes are presented in Appendix 2 (available at www. cmajopen.ca/content/9/3/E818/suppl/DC1).

We conducted 2 scenario analyses to examine the impact of plausible variations in categories of cost inputs on the study results. Variations in scenario cost inputs are presented in Appendix 1.

The base analysis incorporated helicopter travel to St. Theresa Point during ice formation and breakup in the fall and spring months, respectively (average cost per 2-way trip per person multiplied by an estimated $0.2 \mathrm{yr}$ ). In the first scenario analysis, we assumed that outreach clinics did not occur during the fall and spring, and were distributed evenly among summer and winter conditions allowing for boat and winter road travel.

We developed a second scenario to capture increased support needs for transportation for patients who would be unable to take commercial flights to access conventional urban clinics. For physiatry outpatient visits in Manitoba, this involves air ambulance transport. We used the lower estimate of the cost of air ambulance flight ranges per 1-way trip for the scenario. All flight cost inputs for the patient and attendant were replaced with the air ambulance cost.

We analyzed the data using Microsoft Excel and present the results using descriptive statistics.

\section{Ethics approval}

Since this was a modelling study based on quality-assurance data without identification of participants and information available from the public domain, ethics review was waived by the Bannatyne Campus Research Ethics Board, University of Manitoba.

\section{Results}

Thirty-one individual patients were seen in the specialist physiatry outreach clinics. The visits comprised new consultations from local health care providers and Winnipeg-based services, follow-up visits for patients previously seen in consultation in Winnipeg, and follow-up visits for those seen in previous outreach clinics (Table 1).

Table 2 and Table 3 present total costs and per unit costs of outreach clinics compared to standard care in conventional urban clinics. The total cost of providing outreach clinics was $21 \%$ of the estimated cost of standard care. The corresponding values for the 2 sites were 16\% for St. Theresa Point and 29\% for Churchill. When only direct costs were included, outreach clinics cost an estimated $24 \%$ of conventional care costs.

Table 1: Outreach clinic visit and patient characteristics

\begin{tabular}{|lccc|}
\hline Characteristic & $\begin{array}{c}\text { St. Theresa } \\
\text { Point }\end{array}$ & Churchill & Total \\
\hline No. of clinics per site & 3 & 3 & 6 \\
\hline $\begin{array}{l}\text { Total no. of individual } \\
\text { patients }\end{array}$ & 20 & 11 & 31 \\
\hline Total no. of clinic visits & 31 & 17 & 48 \\
\hline \multicolumn{1}{|c|}{ New consultations } & 16 & 10 & 26 \\
\hline \multicolumn{1}{|c|}{ Follow-up visits } & 15 & 7 & 22 \\
\hline $\begin{array}{l}\text { No. of clinic visits for } \\
\text { patients who could not fly } \\
\text { commercially }\end{array}$ & 6 & 3 & 9 \\
\hline $\begin{array}{l}\text { Total no. of attendant } \\
\text { trips }\end{array}$ & 38 & 15 & 53 \\
\hline $\begin{array}{l}\text { Average no. of attendants } \\
\text { per patient trip }\end{array}$ & 1.2 & 0.9 & 1.1 \\
\hline
\end{tabular}




\begin{tabular}{|c|c|c|c|c|c|c|c|c|c|}
\hline \multirow[b]{2}{*}{$\begin{array}{l}\text { Type of } \\
\text { cost }^{*}\end{array}$} & \multicolumn{3}{|c|}{ St. Theresa Point; cost, \$ } & \multicolumn{3}{|c|}{ Churchill; cost, \$ } & \multicolumn{3}{|c|}{ Both centres; cost, \$ } \\
\hline & Outreach & Conventional & $\begin{array}{c}\text { Incremental } \\
\text { cost }\end{array}$ & Outreach & Conventional & $\begin{array}{c}\text { Incremental } \\
\text { cost }\end{array}$ & Outreach & Conventional & $\begin{array}{c}\text { Incremental } \\
\text { cost }\end{array}$ \\
\hline \multicolumn{10}{|l|}{ Direct } \\
\hline Staff & 8895 & 7340 & 1555 & 8834 & 4205 & 4629 & 17729 & 11545 & 6184 \\
\hline Travel & 5416 & 60878 & -55462 & 8043 & 42336 & -34293 & 13459 & 103214 & -89755 \\
\hline Living & 305 & 10463 & -10158 & 305 & 5292 & -4987 & 611 & 15755 & -15144 \\
\hline Subtotal & 14616 & 78682 & -64066 & 17182 & 51833 & -34651 & 31799 & 130514 & -98716 \\
\hline Indirect & 780 & 19012 & -18232 & 557 & 8817 & -8260 & 1337 & 27830 & -26493 \\
\hline Grand total & 15396 & 97694 & -82299 & 17739 & 60650 & -42911 & 33136 & 158344 & -125209 \\
\hline
\end{tabular}

\begin{tabular}{|c|c|c|c|c|c|c|c|c|c|}
\hline \multirow[b]{2}{*}{$\begin{array}{l}\text { Type of } \\
\text { cost* }^{*}\end{array}$} & \multicolumn{3}{|c|}{ St. Theresa Point; cost, \$ } & \multicolumn{3}{|c|}{ Churchill; cost, \$ } & \multicolumn{3}{|c|}{ Both centres; cost, \$ } \\
\hline & Outreach & Conventional & $\begin{array}{l}\text { Incremental } \\
\text { cost }\end{array}$ & Outreach & Conventional & $\begin{array}{l}\text { Incremental } \\
\text { cost }\end{array}$ & Outreach & Conventional & $\begin{array}{l}\text { Incremental } \\
\text { cost }\end{array}$ \\
\hline \multicolumn{10}{|l|}{ Direct } \\
\hline Staff & 287 & 237 & 50 & 520 & 247 & 273 & 369 & 241 & 128 \\
\hline Travel & 175 & 1964 & -1789 & 473 & 2490 & -2017 & 280 & 2150 & -1870 \\
\hline Living & 10 & 338 & -328 & 18 & 311 & -293 & 13 & 328 & -315 \\
\hline Subtotal & 472 & 2539 & -2067 & 1011 & 3049 & -2038 & 662 & 2719 & -2057 \\
\hline Indirect & 25 & 613 & -588 & 33 & 519 & -486 & 28 & 580 & -552 \\
\hline Grand total & 497 & 3152 & -2655 & 1044 & 3568 & -2524 & 690 & 3299 & -2609 \\
\hline
\end{tabular}

\section{Cost distribution}

The cost distribution according to living costs, travel costs, staffing costs and indirect cost of travel as a relative percentage of per unit costs for the 2 communities is presented in Figure 1. The majority of conventional clinic costs was attributable to travel, and travel accounted for the greatest decline in costs for both the St. Theresa Point and the Churchill clinics.

\section{Sensitivity analysis}

The outcomes of the 1-way sensitivity analyses are presented in Figure 2. The incremental cost resulting from changes in single inputs ranged from $-\$ 105523$ to $-\$ 134486$. Results of the cost-minimization analysis were most sensitive to the airplane flight costs and the travel time to visit the conventional clinic.

\section{Scenario analyses}

Scenario analyses results are presented in Table 4. Restricting outreach clinics to times when helicopter flights to St. Theresa Point are not required reduced the costs of outreach clinics in that community from $16 \%$ to $15 \%$ of conventional clinic costs. Including specialized medical transport via air ambulance to a conventional clinic for
4 patients (19\% of clinic visits) reduced costs of outreach clinics from $21 \%$ to $10 \%$ of conventional clinic costs.

\section{Interpretation}

Our cost analysis of physiatry outreach clinics in Manitoba showed substantial cost savings compared to conventional care. The results suggest that, for the direct costs of providing a rural resident with a single physiatrist clinic visit in an urban centre, 4 visits could be provided with a physiatry outreach clinic. When the indirect costs are included, 5 visits could be provided with a physiatry outreach clinic. Accounting for specialized medical transport for some patients to access conventional care suggests that 10 outreach visits could be provided for the cost of 1 conventional visit.

Most of the economic analysis literature regarding care for rural populations focuses on telehealth and e-consultation options. ${ }^{17}$ For patients requiring physiatric care, these emerging services are largely inadequate, as in-person visits are needed for the specialized physical examination (e.g., spasticity assessment, electrodiagnostic testing) and interventional treatments (e.g., injections). ${ }^{15}$ 


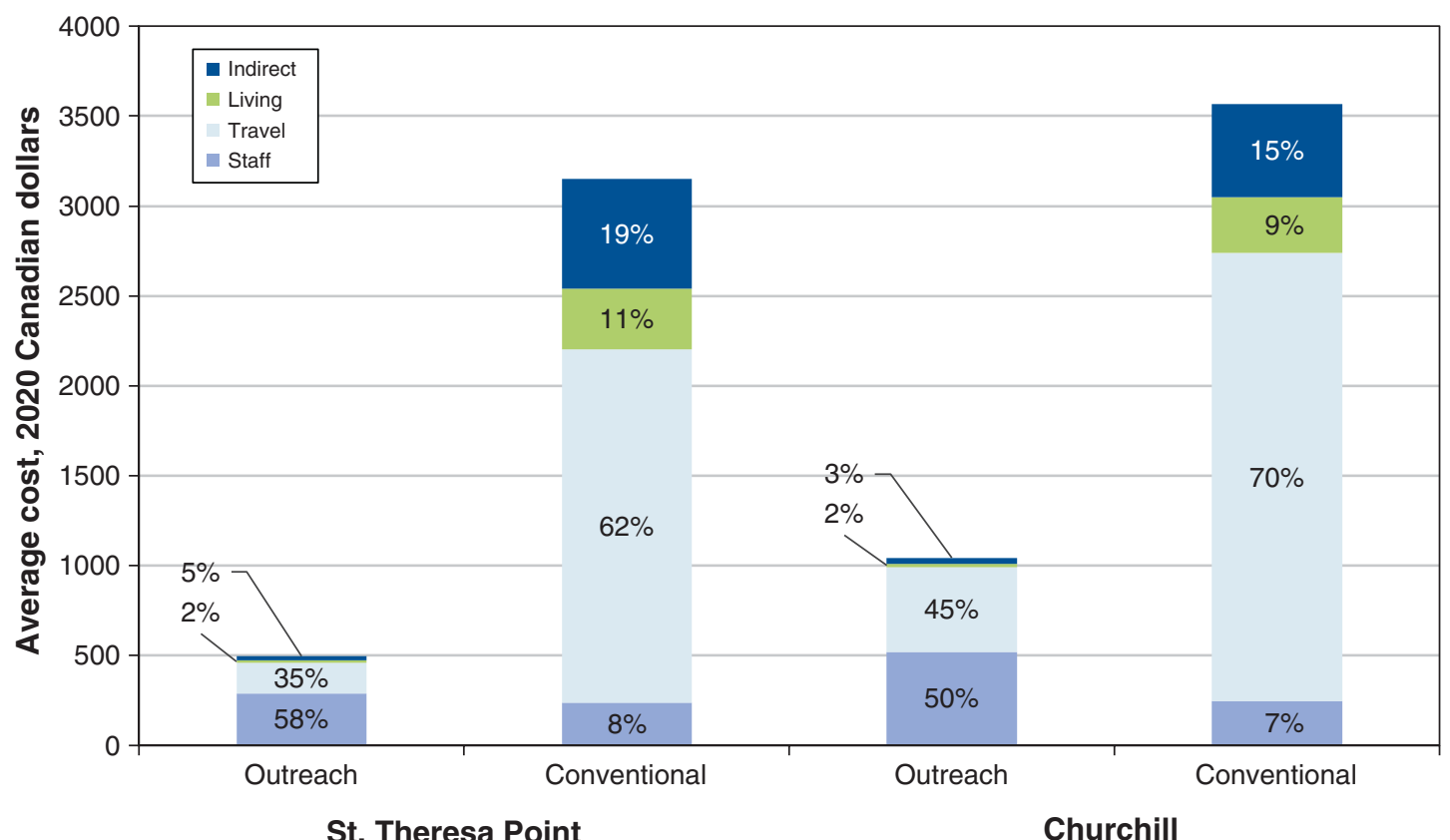

Figure 1: Average total cost per patient visit in outreach clinics and estimated cost in conventional urban clinics, by cost type. Additional details of the type of costs in each category are provided in Appendix 1.

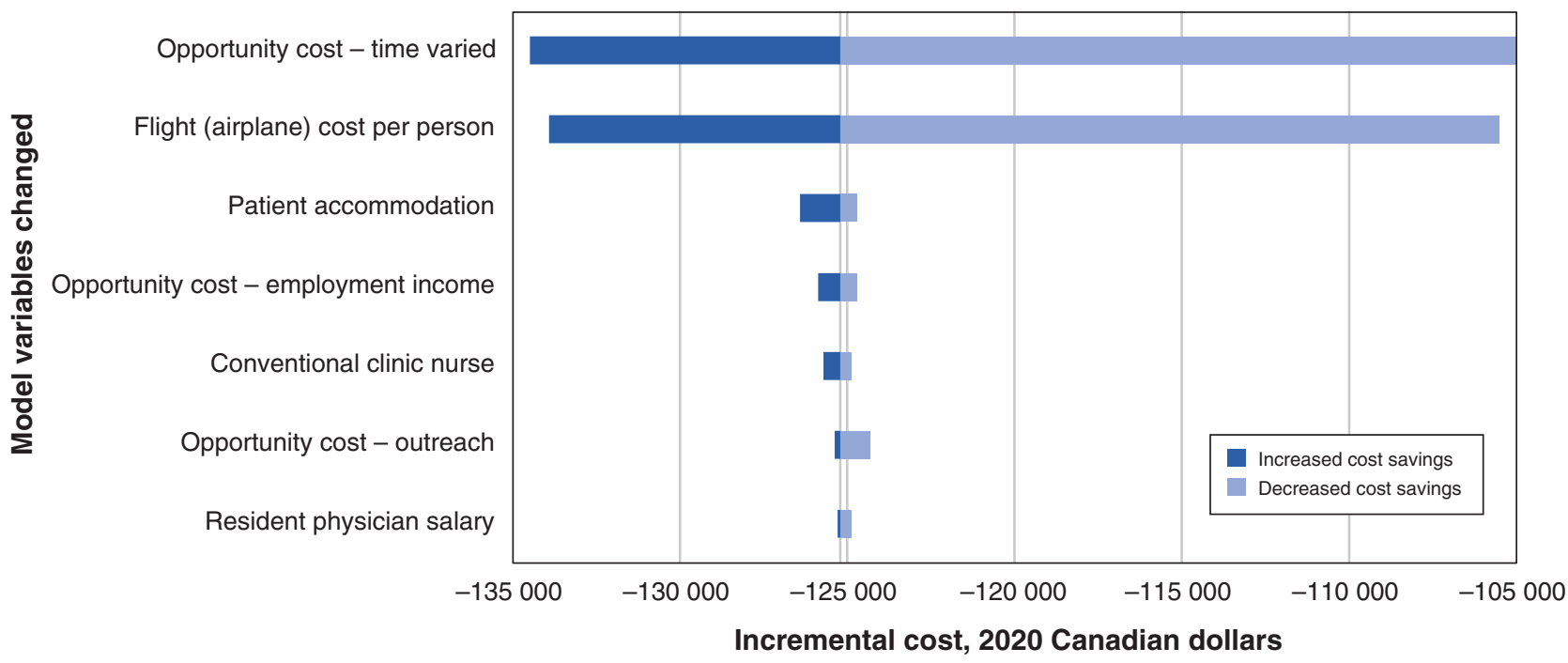

Figure 2: One-way sensitivity analysis of total incremental costs of outreach clinics compared to conventional urban clinics, with cost inputs being varied individually. Base case costs $=\$-125209$. Additional details of the type of costs in each category are provided in Appendix 2 .

High travel costs are concerning and can affect care decisions for patients without travel funding in Canada, especially those in rural settings, who have lower average incomes than people in urban settings. ${ }^{31}$ A cancer care survey in New- foundland and Labrador showed that travel costs were disproportionately important for rural compared to urban patients in making treatment decisions. ${ }^{33}$ For rural patients requiring rehabilitation, limited ability to travel to access 


\begin{tabular}{|c|c|c|c|c|c|c|c|c|c|}
\hline \multirow[b]{2}{*}{ Scenario } & \multicolumn{3}{|c|}{ St. Theresa Point; cost, \$ } & \multicolumn{3}{|c|}{ Churchill; cost, \$ } & \multicolumn{3}{|c|}{ Both centres; cost, \$ } \\
\hline & Outreach & Conventional & $\begin{array}{l}\text { Incremental } \\
\text { cost }\end{array}$ & Outreach & Conventional & $\begin{array}{l}\text { Incremental } \\
\text { cost }\end{array}$ & Outreach & Conventional & $\begin{array}{l}\text { Incremental } \\
\text { cost }\end{array}$ \\
\hline Base case & 15396 & 97694 & -82298 & 17739 & 60650 & -42911 & 33136 & 158344 & -125209 \\
\hline $\begin{array}{l}\text { Excluding } \\
\text { helicopter } \\
\text { travel for } \\
\text { outreach } \\
\text { clinics }\end{array}$ & 14318 & 97694 & -83376 & NA & NA & NA & NA & NA & NA \\
\hline $\begin{array}{l}\text { Including air } \\
\text { ambulance } \\
\text { for } \\
\text { conventional } \\
\text { clinics }\end{array}$ & 15396 & 220706 & -205310 & 17739 & 117084 & -99345 & 33136 & 337790 & -304655 \\
\hline
\end{tabular}

urban physiatric care owing to cost or complexity increases the risk of chronic complications, resulting in inpatient admissions, morbidity and death. ${ }^{7,14}$ A specialist physiatry outreach clinic therefore also may have long-term implications for health system costs and access.

Other reports of rural outreach care provided in different formats generally showed reduced costs (converted here into 2020 Canadian dollars). This includes the cost per visit of combined specialist outreach compared to regional and urban care in Australia (\$382 v. \$492 and \$620, respectively), ${ }^{34}$ the cost per outreach cataract procedure compared to procedures performed in an urban hospital in the United Kingdom (\$169 v. \$256), ${ }^{20}$ and the net annual costs per patient at 2 rural hospitals and 1 urban hospital managing patients with cancer after implementation of a rural cancer outreach program in the United States (\$8421 v. \$22 313 before implementation). ${ }^{35}$ However, Oboler and colleagues ${ }^{36}$ reported similar costs with internal medicine outreach and care at an urban medical centre in the US (\$260 v. \$256). Physiatric care commonly generates follow-up investigations or referrals, necessitating travel to the urban setting, which could offset costs savings of outreach services. However, in the Manitoba physiatry experience, the coordination of additional care rarely occurs during the same trip to Winnipeg, necessitating an additional trip at a later date.

Additional research is needed to further examine the temporal variation of travel costs and patient demographic characteristics in providing care through outreach services. Including other physiatry outreach services in Canada would help generalize incremental cost estimates across various settings and with telehealth integration. Despite the comprehensive inclusion of physician services in Canadian public health care, payers for rural communities and populations can be complex. Delineating the incremental costs among provincial, federal and patient payers can further inform policy.
The Manitoba physiatry outreach clinics likely increased access, especially for patients requiring air ambulance transport; however, data on effectiveness would further inform the implications for health care system costs, including increased costs from further referral and use of health care services. ${ }^{17,34}$ Investigation of process measures should be patient-centred and include access, use and satisfaction. These process outcomes have known challenges within a rural context, with lack of infrastructure; limited communication between hospitals and rural health care services; health care professionals' perceptions that outreach is associated with lower efficiency; higher costs to professionals; doctor-patient communication, which can be impaired by specialist physicians' lack of experience of the rural context and disconnect with patient experience (e.g., difficulty understanding the context of wheelchair users' mobility in communities without paved roads or sidewalks); and cultural differences. ${ }^{11,19-21}$

Health care system costs are influenced by long-term health outcomes. Quantifying change in health outcomes from outreach physiatry care in maintaining quality of life and preventing inpatient admissions, morbidity and death, and at what cost, will likely be the most important future evaluation of this care model. Further exploration of the impact of carbon emissions resulting from lengthy air and land travel to access health care would be important to understand the environmental impact of delivering care to people in rural settings.

\section{Limitations}

Our relatively small sample did not allow us to examine the impact of uncertainty of analysis inputs. In addition, it may not be fully representative of the rural population requiring physiatric services. The short follow-up duration may not be representative of the costs of an ongoing established service, which would likely be less, and precluded outcome evaluation. Outreach and conventional clinics were considered in isolation 
of their fixed overhead costs, which may vary between the health centres studied despite similar care provision.

Estimating opportunity costs of travel time is complex; this cost as an indirect cost may be considered differently by different public payers. One-way analyses are intended to identify which specific model inputs are the most sensitive when varied; however, they do not indicate interactions, the potential nonlinearity of values or the likelihood that a given value is correct. In our analysis, there were only 2 highly sensitive inputs - flight cost and indirect cost of travel time - and these variables are not expected to interact.

Finally, the applicability and sustainability of outreach service models are specialist- and community-specific. Given the heterogeneous Canadian environment, adaptation of outreach services based on interest, support, access and rehabilitation populations will influence effectiveness.

\section{Conclusion}

Our societal cost-minimization analysis showed that outreach physiatry clinics in remote communities in Manitoba represented $21 \%$ of the estimated costs of providing conventional care for these patients in an urban outpatient setting. The costs savings of outreach services ranged from \$105 523 to $\$ 134486$ when flight cost was varied as the most sensitive direct cost. The majority of costs savings was related to travel, and varied with season and patient care needs. Physician services in Canada are primarily paid for by the public health care system, and, for rural patients, often include travel funding. Understanding influence on health outcomes is a critical next step in evaluating this form of specialist outreach, contextualizing it among telehealth services and conventional care in providing access to outpatient rehabilitation for those with chronic conditions.

\section{References}

1. Morris S, Fawcett G, Brisebois L, et al. A demographic, employment and income profile of Canadians with disabilities aged 15 years and over, 2017. Cat no 89-654X2018002. Ottawa: Statistics Canada; 2018. Available: https://www150.statcan. gc.ca/n1/pub/89-654-x/89-654-x2018002-eng.htm (accessed 2020 Apr. 29).

2. National Spinal Cord Injury Statistical Center. 2012 annual statistical report for the Spinal Cord Injury Model Systems - complete public version. Birmingham (AL): University of Alabama at Birmingham; 2013. Available: https://www.nscisc.uab. edu/PublicDocuments/reports/pdf/2012\%20NSCISC\%20Annual\%20Statistical \%20Report\%20Complete\%20Public\%20Version.pdf (accessed 2020 Apr. 29).

3. Dennis MS, Burn JP, Sandercock PA, et al. Long-term survival after first-ever stroke: the Oxfordshire Community Stroke Project. Stroke 1993;24:796-800.

4. Table 17-10-0135-01: Population estimates, fuly 1, by census metropolitan area and census agglomeration, 2016 boundaries. Ottawa: Statistics Canada. Available: www150. statcan.gc.ca/t1/tbl1/en/tv.action?pid=1710013501 (accessed 2020 Apr. 29).

5. Wilkinson R, Marmot M, editors. Social determinants of bealth: the solid facts. 2 nd ed. Copenhagen: WHO Regional Office for Europe; 2003. Available: https:// www.euro.who.int/_data/assets/pdf_file/0005/98438/e81384.pdf (accessed 2020 Apr. 29)

6. Keightley ML, Ratnayake R, Minore B, et al. Rehabilitation challenges for aboriginal clients recovering from brain injury: a qualitative study engaging health care practitioners. Brain Inj 2009;23:250-61.

7. Wearmouth H, Wielandt T. "Reserve is no place for a wheelchair": challenges to consider during wheelchair provision intended for use in First Nations community. Disabil Rebabil Assist Technol 2009;4:321-8.

8. Honouring the truth, reconciling for the future: summary of the final report of the Truth and Reconciliation Commission of Canada. Toronto: Truth and Reconciliation Commission of Canada; 2015. Available: https://publications.gc.ca/collections/ collection_2015/trc/IR4-7-2015-eng.pdf (accessed 2021 Aug. 16).

9. Allan B, Smylie J. First Peoples, second class treatment: the role of racism in the bealth and well-being of Indigenous peoples in Canada. Executive summary. Toronto: Wellesley Institute; 2015. Available: www.wellesleyinstitute.com/wp-content/
uploads/2015/02/Summary-First-Peoples-Second-Class-Treatment-Final.pdf (accessed 2020 Apr. 29).

10. King M, Smith A, Gracey M. Indigenous health part 2: the underlying causes of the health gap. Lancet 2009;374:76-85.

11. Canada Health Act (R.S.C., 1985, c. C-6). Available: https://laws-lois.justice. gc.ca/PDF/C-6.pdf (accessed 2020 Apr. 29)

12. Keightley ML, King GE, Jang SH, et al. Brain injury from a First Nations' perspective: teachings from elders and traditional healers. Can 7 Occup Ther 2011;78:237-45.

13. Haozous EA, Doorenbos AZ, Stoner S. Pain management experiences and the acceptability of cognitive behavioral strategies among American Indians and Alaska Natives. 7 Transcult Nurs 2016;27:233-40.

14. Frier A, Barnett F, Devine S. The relationship between social determinants of health, and rehabilitation of neurological conditions: a systematic literature review. Disabil Rehabil 2017;39:941-8.

15. Martinez RN, Hogan TP, Lones K, et al. Evaluation and treatment of mild traumatic brain injury through the implementation of clinical video telehealth: provider perspectives from the Veterans Health Administration. PMR 2017;9:231-40.

16. Powell J. Systematic review of outreach clinics in primary care in the UK. $\mathcal{F}$ Health Serv Res Policy 2002; 7:177-83.

17. Gruen RL, Weeramanthri TS, Knight SE, et al. Specialist outreach clinics in primary care and rural hospital settings. Cochrane Database Syst Rev 2003;(1): CD003798.

18. Howe HL, Lehnherr M, Katterhagen JG. Effects of physician outreach programs on rural-urban differences in breast cancer management. 7 Rural Health 1997;13:109-17.

19. O'Brien K, Mattick R, Mandall N, et al. Are specialist outreach clinics for orthodontic consultation effective? A randomised controlled trial. Br Dent 7 2001; 191:203-7.

20. Haynes R, Gale S, Mugford M, et al. Cataract surgery in a community hospital outreach clinic: patients' costs and satisfaction. Soc Sci Med 2001;53:1631-40.

21. Kapp KW. The social costs of business enterprise. Revised and extended ed. Nottingham (UK): Spokesman; 1978. Available: www.kwilliam-kapp.de/documents/ SCOBE_000.pdf (accessed 2020 Aug. 3).

22. Loane MA, Oakley A, Rademaker M, et al. A cost-minimization analysis of the societal costs of realtime teledermatology compared with conventional care: results from a randomized controlled trial in New Zealand. 7 Telemed Telecare 2001;7:233-8.

23. Scuffham PA, Steed M. An economic evaluation of the Highlands and Islands teledentistry project. 7 Telemed Telecare 2002;8:165-77.

24. Smith AC, Stathis S, Randell A, et al. A cost-minimization analysis of a telepaediatric mental health service for patients in rural and remote Queensland. 7 Telemed Telecare 2007;13(3 Suppl):79-83.

25. Driving costs calculator. Ottawa: Canadian Automobile Association. Available: https://carcosts.caa.ca/ (accessed 2019 Sept. 14).

26. Shah JN. Taking specialist surgical services to the rural district hospitals at one forth [sic] cost: a sustainable 'return on investment' public health initiative of Patan Hospital, Patan Academy of Health Sciences, Nepal. Kathmandu Univ Med 7 (KUM7) 2015;13:186-92.

27. Schedule of compensation for the Manitoba Public Sector Compensation Disclosure Act of Winnipeg Regional Health Authority. Winnipeg: Deloitte; 2018. Available: https://wrha.mb.ca/files/public-compensation-disclosure-2018.pdf (accessed 2020 Apr. 14).

28. Minister of Health. Manitoba physician's manual. Winnipeg: Government of Manitoba; 2020. Available: www.gov.mb.ca/health/documents/physmanual.pdf (accessed 2020 Apr. 14).

29. Professional Association of Residents and Interns of Manitoba; Winnipeg Regional Health Authority. Collective agreement fuly 1, 2014 to fune 30, 2018. Winnipeg: Professional Asssociation of Residents and Interns of Manitoba; 2015. Available: https://parim.org/wp-content/uploads/2015/06/PARIM -Collective-Agreement-2014-2018-OSB.pdf (accessed 2019 Sept. 14).

30. Professional Association of Residents and Interns of Manitoba; Shared Health. Collective agreement Fuly 1, 2018 to Fune 30, 2021. Winnipeg: Professional Association of Residents and Interns of Manitoba; 2018. Available: https:// www.parim.org/wp-content/uploads/2020/06/2018-2021-PARIM-Collective -Agreement-Final-signed-3.pdf (accessed 2020 July 13).

31. Table 11-10-0239-01: Income of individuals by age group, sex and income source, Canada, provinces and selected census metropolitan areas. Ottawa: Statistics Canada. Available: www150.statcan.gc.ca/t1/tbl1/en/tv.action?pid=1110023901 (accessed 2020 Apr. 29).

32. Inflation calculator. Ottawa: Bank of Canada. Available: www.bankofcanada.ca/ rates/related/inflation-calculator/ (accessed 2020 Apr. 29).

33. Mathews M, West R, Buehler S. How important are out-of-pocket costs to rural patients' cancer care decisions? Can 7 Rural Med 2009;14:54-60.

34. Gruen RL, Bailie RS, d'Abbs PH, et al. Improving access to specialist care for remote Aboriginal communities: evaluation of a specialist outreach service. Med 7 Aust 2001;174:507-11.

35. Desch CE, Grasso MA, McCue MJ, et al. A rural cancer outreach program lowers patient care costs and benefits both the rural hospitals and sponsoring academic medical center. 7 Rural Health 1999;15:157-67.

36. Oboler SK, Blieden MA, Carter SA, et al. A mobile internal medicine clinic. Arch Intern Med 1983;143:97-9. 
Affiliations: Section of Physical Medicine and Rehabilitation (Reid, Ethans), Department of Internal Medicine, University of Manitoba, Winnipeg, Man.; KITE - Toronto Rehabilitation Institute (Chan), University Health Network; Institute of Health Policy, Management and Evaluation (Chan), University of Toronto, Toronto, Ont.

Contributors: Janine Reid and Karen Ethans contributed to study conception and design, and data acquisition. Janine Reid and Brian Chan analyzed and interpreted the data. Janine Reid drafted the manuscript. All of the authors participated in revising the manuscript critically for important intellectual content, approved the final version to be published and agreed to be accountable for all aspects of the work.

Funding: This work was supported by a Health Sciences Centre Medical Staff Fellowship Fund Travel Grant.

Content licence: This is an Open Access article distributed in accordance with the terms of the Creative Commons Attribution (CC BY-NCND 4.0) licence, which permits use, distribution and reproduction in any medium, provided that the original publication is properly cited, the use is noncommercial (i.e., research or educational use), and no modifications or adaptations are made. See: https://creativecommons.org/licenses/by-nc -nd/4.0/

Data sharing: The data for this study are held securely by the corresponding author. Further information and requests for access to data should be addressed to her.

Acknowledgements: The authors thank Janice Linton, Indigenous health liaison librarian, University of Manitoba, Amanda Abele, consultant program coordinator and administrator, Ongomiizwin Health Services, University of Manitoba, and the Section of Physical Medicine and Rehabilitation Journal Club, University of Manitoba for their assistance in developing this project and the manuscript.

Supplemental information: For reviewer comments and the original submission of this manuscript, please see www.cmajopen.ca/content/9/3/ E818/suppl/DC1. 